\title{
Screening of exon 11 of BRCA1 gene using the high resolution melting approach for diagnosis in Moroccan breast cancer patients
}

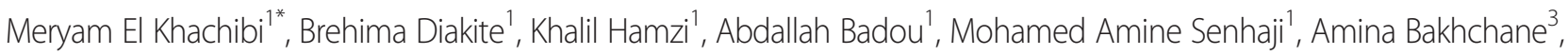
Hassan Jouhadi ${ }^{2}$, Abdelhamid Barakat ${ }^{3}$, Abdellatif Benider ${ }^{2}$ and Sellama Nadifi ${ }^{1}$

\begin{abstract}
Background: Identification of specific mutations in cancer patients may lead to the discovery of genes, which can affect susceptibility and/or prognosis. It has previously been reported that mutations in BRCA1 and BRCA2 genes are linked to breast cancer. Here, we evaluated the use of the High Resolution Melting (HRM) approach to screen for mutations in exon 11 of BRCA1 gene in Moroccan patients.

Methods: HRM analysis was used to screen exon 11 from 71 breast cancer patients in order to detect different variants. Conventional Sanger sequencing was used to confirm the presence of possible mutations. Distribution of different SNPs was determined by SNaPshot analysis software.

Results: In order to assess the efficacy of the HRM approach to screen for mutations, especially in diagnosis, we first used two samples with previously known mutations, "2924delA and 3398delC". Indeed, these previously known sequence variants were detected by the HRM approach and yielded melting curves with atypical shape relative to wild-type control sequences. We then analyzed, 69 samples from breast cancer patients using the HRM method, and were able to detect two samples with atypical curves. Sequencing of the two samples, using the conventional Sanger approach, confirmed the presence of the same SNP (c.2612C > T) in both samples.

Conclusions: Our results strongly suggest that the HRM approach represents a reliable and highly sensitive method for mutation scanning, especially in diagnosis.
\end{abstract}

Keywords: Breast cancer, BRCA1, Exon 11, HRM

\section{Background}

$B R C A 1$ is a tumor suppressor gene located on chromosome 17 , position $17 \mathrm{q} 21$ in humans. It is comprised of 24 exons spread over $81 \mathrm{~kb}$ of DNA, 22 of which are coding exons. These exons encode a transcript of about 7000 bp translated into a protein of 1863 amino acids [1]. Exon 11 of $B R C A 1$ is a large central exon of $3426 \mathrm{bp}$. This exon represents $60 \%$ of the coding sequence.

Nowadays, it is common knowledge that germ-line mutations of the BRCA1 gene are high risk factors for developing breast cancer [2]. Since the identification of this particular gene two decades ago [3], it is now

\footnotetext{
* Correspondence: el.khachibi.meryam@gmail.com

'Genetics and Molecular Pathology Laboratory, Medical school of Casablanca, Casablanca, Morocco

Full list of author information is available at the end of the article
}

frequently used in prognosis worldwide, in women with breast and ovarian hereditary predisposition syndrome [4].

Although Sanger sequencing remains the most reliable technique to identify sequence variants, this approach is costly and time consuming. In order to establish an accurate prognosis in breast cancer patients through the identification of BRCA1 sequence variants, a number of specific screening procedures, which are both cost- and time- effective have been developed [1].

In Morocco, conventional sequencing techniques have been used to sequence $B R C A 1[5,6]$. However, sequencing is quite expensive and since Morocco is a low-income country, most of its patients can't afford this type of check-up.

The HRM method is a scanning technique that enables mutation scanning and amplification to be performed readily, and in one step [2]. This is a method in which only 
primers and fluorescent DNA binding dye are used, and no sample processing (after PCR amplification) is required [7]. It is important to note that the HRM technique also allows heteroduplex detection.

Several studies have been conducted to scan BRCA1 exons by the HRM approach [2,8-11]. However, to our knowledge, this is the first study performed in Morocco using the HRM approach to screen the BRCA1 gene.

Our aim was to explore the reliability of the HRM approach for the identification of $B R C A 1$ mutation carriers in exon 11 among family members of an index patient (IP); and to search for the presence of new genetic variants in the Moroccan population. In the first part of this study, we analyzed and detected, using the HRM approach, variants from samples of patients presenting with breast cancer. In the second part, we corroborated the results (obtained by the HRM method) using the standard Sanger sequencing technique.

\section{Methods}

\section{Patients and samples}

We started our work with two previously sequenced, positive controls (2924delA and 3398delC). 71 patients, found positive for breast cancer through clinical and histological examinations, were recruited from private and public oncology centers of Casablanca from 2009 to 2010. Five more donors were used as negative healthy controls.

Experiments performed in this study were evaluated and approved by the Ethic Committee for Biomedical Research in Casablanca (CERBC) of the Faculty of Medicine and Pharmacy ( $\left.\mathrm{N}^{\circ} 121\right)$. For this purpose, a written consent (including the agreement to publish clinical data) was given by each study participant (patient and control).

DNA was extracted using the phenol-chloroform method as previously described, [12] and quantified using the NanoVue ${ }^{\mathrm{Tm}}$ Plus Spectrophotometer (GE Healthcare, UK).

\section{HRM protocol}

Assays were performed in 96 well plates. Amplification by PCR, of exon 11 of BRCA1 was performed using primers reported by P. D. Murphy in 2005 (see Table 1) [13] using a 7500 Fast Real-Time PCR system (AB Applied Biosystems, USA). Analysis of the obtained curves was performed using the 7500 Fast System SDS v2.0.1 software.

Table 1 List of primers used to amplify the BRCA1 gene exon 11

\begin{tabular}{|c|c|c|c|}
\hline Gene & & Sequence & Taille \\
\hline$\overline{\text { BRCA1 }}$ & Forward primer & 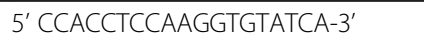 & $372 \mathrm{bp}$ \\
\hline exon $11 \mathrm{~A}$ & Reverse primer & 5' TGTTATGTTGGCTCCTTGCT-3' & \\
\hline BRCA1 & Forward primer & $5^{\prime}$ CACTAAAGACAGAATGAATCTA-3' & $400 \mathrm{bp}$ \\
\hline exon $11 \mathrm{~B}$ & Reverse primer & 5' GAAGAAGCAGAATATTCATCTA-3' & \\
\hline BRCA1 & Forward primer & 5' TGATGGGGAGTCTGAATCAA-3' & $400 \mathrm{bp}$ \\
\hline exon $11 \mathrm{C}$ & Reverse primer & 5' TCTGCTITCTTGATAAAATCCT-3' & \\
\hline BRCA1 & Forward primer & 5' AGCGTCCCCTCACAAATAAA-3' & $400 \mathrm{bp}$ \\
\hline exon $11 \mathrm{D}$ & Reverse primer & $5^{\prime}$ TCAAGCGCATGAATATGCCT-3' & \\
\hline BRCA1 & Forward primer & 5' GTATAAGCAATATGGAACTCGA-3' & $388 \mathrm{bp}$ \\
\hline exon $11 \mathrm{E}$ & Reverse primer & $5^{\prime}$ TTAAGTTCACTGGTATTTGAACA-3' & \\
\hline BRCA1 & Forward primer & 5' GACAGCGATACTTTCCCAGA-3' & $382 \mathrm{bp}$ \\
\hline exon $11 \mathrm{~F}$ & Reverse primer & $5^{\prime}$ TGGAACAACCATGAATTAGTC-3' & \\
\hline BRCA1 & Forward primer & 5' GGAAGTTAGCACTCTAGGGA-3' & $423 \mathrm{bp}$ \\
\hline exon $11 \mathrm{G}$ & Reverse primer & 5' GCAGTGATATTAACTGTCTGTA-3 & \\
\hline BRCA1 & Forward primer & $5^{\prime}$ TGGGTCCTTAAAGAAACAAAGT-3' & $366 \mathrm{bp}$ \\
\hline exon $11 \mathrm{H}$ & Reverse primer & 5' TCAGGTGACATTGAATCTTCC-3' & \\
\hline BRCA1 & Forward primer & $5^{\prime}$ CCACTIITTCCCATCAAGTCA-3' & $377 \mathrm{bp}$ \\
\hline exon 11 I & Reverse primer & 5' TCAGGATGCTTACAATTACTTC-3' & \\
\hline BRCA1 & Forward primer & 5' CAAAATTGAATGCTATGCTTAGA-3' & $377 \mathrm{bp}$ \\
\hline exon $11 \mathrm{~J}$ & Reverse primer & 5' TCGGTAACCCTGAGCCAAAT-3' & \\
\hline BRCA1 & Forward primer & 5' GCAAAAGCGTCCAGAAAGGA-3' & $396 \mathrm{bp}$ \\
\hline exon $11 \mathrm{~K}$ & Reverse primer & 5' TATITGCAGTCAAGTCTTCCAA-3' & \\
\hline BRCA & Forward primer & 5' GTAATATTGGCAAAGGCATCT-3' & $360 \mathrm{bp}$ \\
\hline exon $11 \mathrm{~L}$ & Reverse primer & 5' TAAAATGTGCTCCCCAAAAGCA-3' & \\
\hline
\end{tabular}




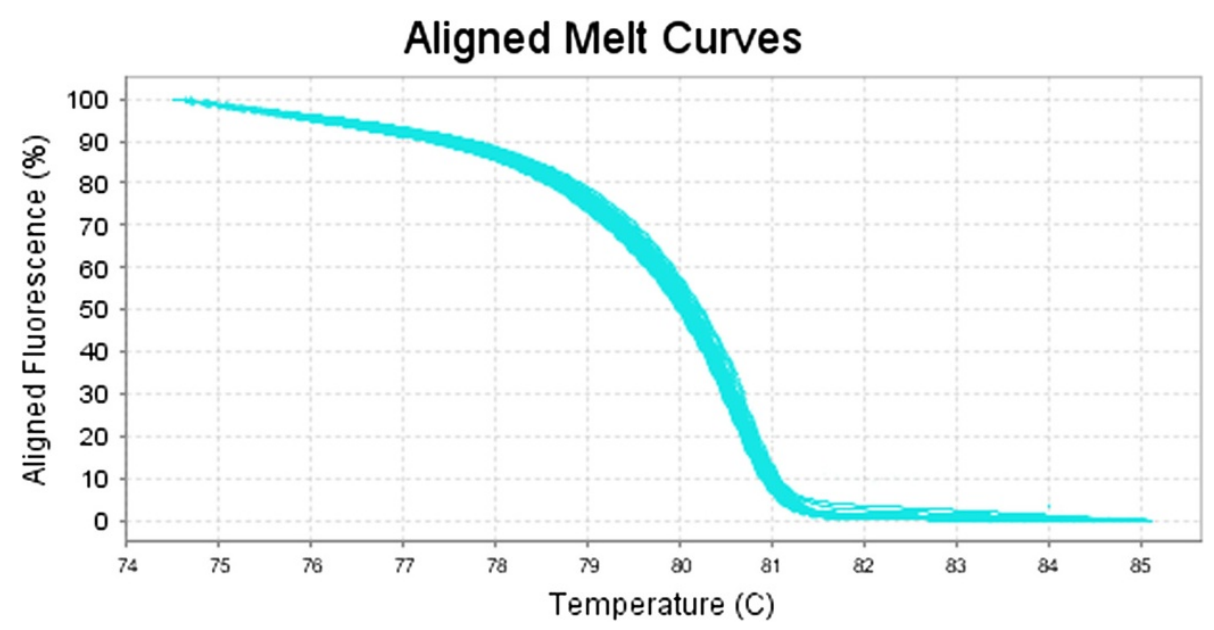

Figure 1 Aligned melt curves of 71 patients.

In these experiments, we used MeltDoctor ${ }^{\mathrm{Tm}} \mathrm{HRM}$ Master Mix kit reagents, which contain HRM SYTO9, a DNA intercalating fluorescent agent (BIOLINE, LONDON, $\mathrm{UK})$. The final volume in the reaction mixture is $20 \mu \mathrm{l}$ (4.4 $\mu \mathrm{l}$ of water, $10 \mu \mathrm{l}$ of Master Mix, $0.25 \mu \mathrm{l}$ of each primer $(10 \mu \mathrm{M})$ and $20 \mathrm{ng}$ of genomic DNA). The HRM protocol was set as follows:

- One cycle of $95^{\circ} \mathrm{C}$ for $10 \mathrm{~min}$;

- 40 cycles of $95^{\circ} \mathrm{C}$ for $10 \mathrm{~s}, 63^{\circ} \mathrm{C}$ for $30 \mathrm{~s}$ and $72^{\circ} \mathrm{C}$ for $20 \mathrm{~s}$;

- One cycle of melt curve of $95^{\circ} \mathrm{C}$ for $10 \mathrm{~s}, 60^{\circ} \mathrm{C}$ for $1 \mathrm{~min}, 95^{\circ} \mathrm{C}$ for $15 \mathrm{~s}$ and $60^{\circ} \mathrm{C}$ for $15 \mathrm{~s}$. In these experiments, we used the same $\mathrm{Tm}$ of $63^{\circ} \mathrm{C}$ for all the primers.

\section{DNA sequencing}

To validate the HRM method, we reanalyzed all of the samples that yielded atypical curves, using conventional Sanger sequencing. These DNA samples were first amplified in a final volume of $25 \mu$ l containing: $5 \times$ reaction buffer, $1.5 \mathrm{mM} \mathrm{MgCl} 2,50 \mu \mathrm{M}$ primers (same primers used for HRM method), $0.25 \mathrm{U}$ Taq polymerase (BIOLINE, LONDON, UK) and 50 ng of genomic DNA.

All the PCR products were treated with exonuclease I and shrimp alkaline phosphatase enzymes prior to sequencing according to the following protocol: $37^{\circ} \mathrm{C}$ for $40 \mathrm{~min}$ and $80^{\circ} \mathrm{C}$ for $15 \mathrm{~min}$. Then, the obtained PCR products were sequenced using the forward primer, the BigDye Terminator v 1.1Standard Kit (Applied Biosystems, Foster City, CA, USA), and the sequencher 3100 ABI Applied Biosystems. With regard to the analysis, we used the Applied Biosystems SeqScape Software v2.5 SNaPshot analysis.

\section{Results}

The first step of this work was to validate the HRM approach for the entire sequence of the Exon 11 of $B R C A 1$ gene. In order to accomplish this, we used DNA samples from five healthy control donors to amplify all
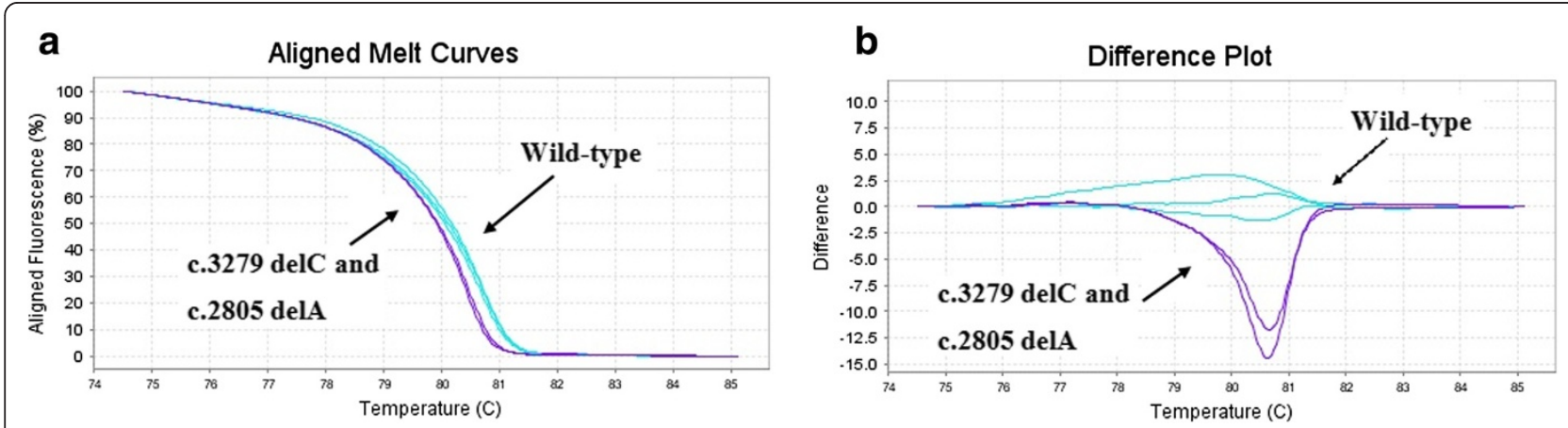

Figure 2 Difference plots of region $\mathrm{H}$ of the BRCA1 gene exon 11 between wild-type and c.3279delC and 2805delA mutations (a and b). 


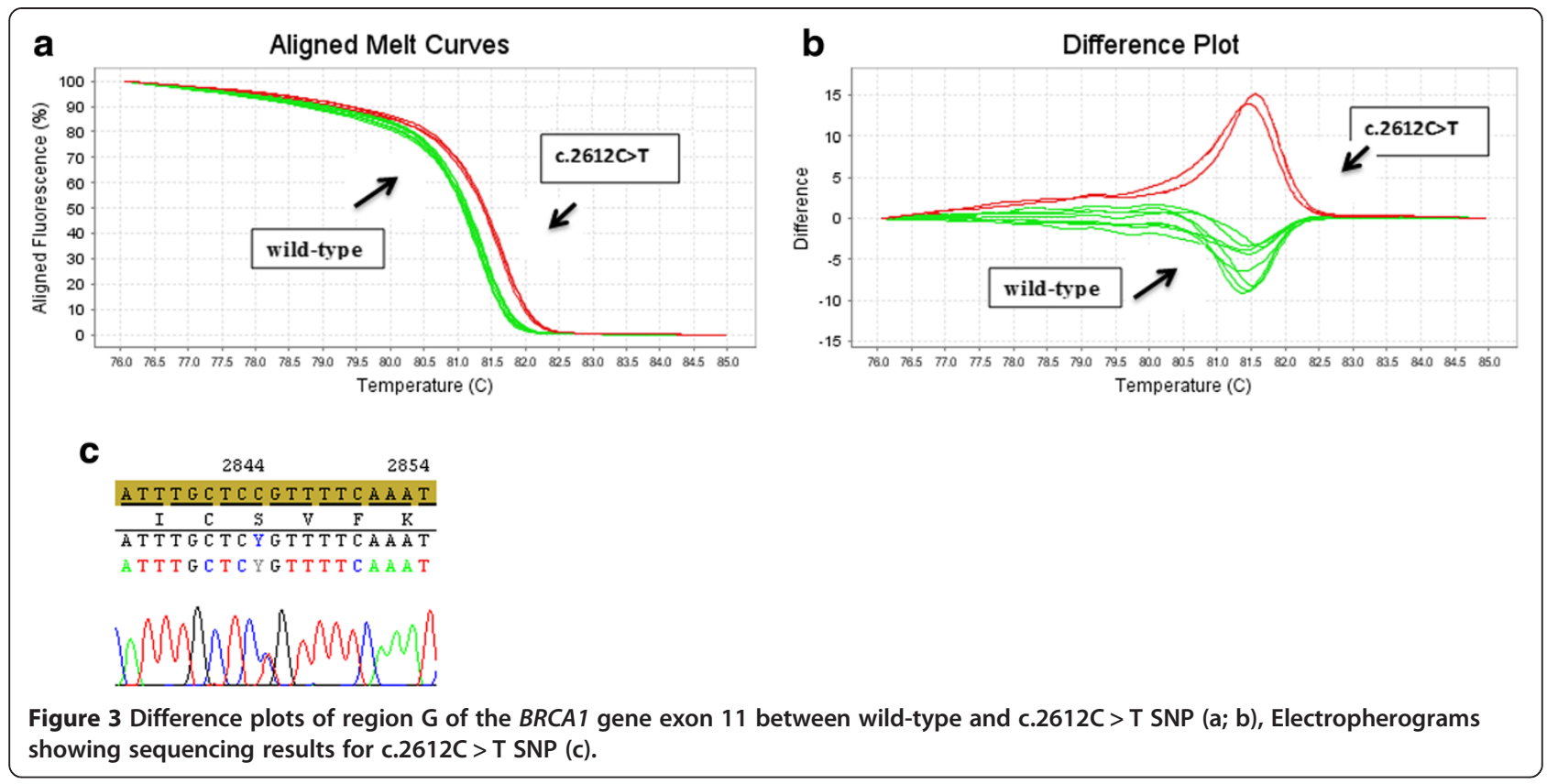

these indicated regions. We also used two positive control DNA samples, in which mutations had previously been detected within the region $\mathrm{H}$ of exon 11 (see Table 1) [5]. As expected, all sequence variants in which mutations were previously detected yielded melting curves with abnormal shapes relative to wild-type DNA. In order to corroborate our observation, we sequenced the two samples that exhibited atypical curves, and found that these samples possessed a SNP. Indeed, The B, C, D, E, F, $\mathrm{I}, \mathrm{K}$ and $\mathrm{L}$ regions of exon 11 (see Table 1 ) did not show atypical curves (Figure 1); whereas the $\mathrm{G}$ and $\mathrm{H}$ regions of exon 11 (see Table 1) exhibited different atypical curves (Figures 2 and 3). All of these variants have been sequenced except for the samples $\mathrm{Br} 23$ and $\mathrm{Br} 24$, already known to carry mutations in the region $\mathrm{H}$ of exon 11 (see Table 2 for details).

Our work has shown that the HRM approach is sensitive, specific and straightforward. This method would also help to avoid costly systematic sequencing. In fact, sequencing, in this case, would be performed only for regions with atypical curves.

\section{Discussion}

In order to detect potential mutations and, at the same time, avoid sequencing the entire BRCA1 gene, several alternate methods have been suggested to screen this gene. For instance, De Leener, et al. used the Protein Truncation Test (PTT), denaturing Gradient Gel Electrophoresis (DGGE) and denaturing High-Performance Liquid Chromatography (dHLPC), followed by specific region sequencing [8]. While all these methods were considered to be relatively sensitive, these approaches, especially the PTT, were shown to be unable to detect all of the mutations [11]. The purpose of our study was to evaluate the efficacy of the HRM method in screening large sequences for potential mutations.

The High Resolution DNA Melting Analysis was first described by Zhou et al. [14], where the authors analyzed the $\Delta \mathrm{F} 508$ mutation associated with the Mucoviscidosis disease. These authors also analyzed, using the same approach, other mutations found in the factor $\mathrm{V}$ gene: $\mathrm{F} 508 \mathrm{C}$ variants in exon 10; and G551D, G542X, and R553X variants in exon 11.

Table 2 All mutations and SNPs detected by the HRM approach were validated using Sanger sequencing method

\begin{tabular}{|c|c|c|c|c|c|c|c|c|c|c|}
\hline Gene & $\begin{array}{l}\text { Patient } \\
\text { code }\end{array}$ & Exon & $\begin{array}{l}\text { HRM } \\
\text { result }\end{array}$ & $\begin{array}{l}\text { Sequencing } \\
\text { result }\end{array}$ & $\begin{array}{l}\text { Mutation } \\
\text { type }\end{array}$ & $\begin{array}{l}\text { Systematic } \\
\text { nomenclature }\end{array}$ & SNP & $\begin{array}{l}\text { Manifestation, } \\
\text { age at diagnosis }\end{array}$ & $\begin{array}{l}\text { Family } \\
\text { history }\end{array}$ & $\begin{array}{l}\text { Ethnic } \\
\text { origin }\end{array}$ \\
\hline \multirow[t]{4}{*}{ BRCA1 } & $\mathrm{Br} 23$ & $11 \mathrm{H}$ & Positive & Positive & c.2805delA & 2924delA & - & $B C, 41 y$ & M aunt, BC $42 \mathrm{y}$ & Berber \\
\hline & $\mathrm{Br} 24$ & $11 \mathrm{H}$ & Positive & Positive & c.3279delC & 3398delC & - & $B C, 32 y$ & Mother, BC 49 y & Berber \\
\hline & $\operatorname{Br} 123$ & $11 \mathrm{G}$ & Positive & Positive & - & - & c. $2612 C>T$ & $B C, 64 y$ & No Family History & Berber \\
\hline & $\mathrm{Br} 12$ & $11 \mathrm{G}$ & Positive & Positive & _- & _ & c. $2612 C>T$ & $B C, 27 y$ & No Family History & Arab \\
\hline
\end{tabular}


Regarding BRCA1 gene screening by the HRM technique, several groups have reported, in agreement with this work, that this method enables the detection of variants $[1,2,8,10,11,15,16]$. In these reports, positive controls were also used to confirm the specificity and sensitivity of this technique $[1,2,8,10,11,15,16]$. In 2009 , De Juan, et al. used the HRM method followed by sequencing to scan for mutations in the BRCA1 and BRCA2 genes [11]. Furthermore, in 2011, the same team reported various advantages of the HRM analysis, and confirmed that this method is much faster than Conformation Sensitive Gel Electrophoresis (CSGE) screening [4]. Altogether, these reports are in agreement with this study, and indicate that the HRM approach is suitable as a primary screening method of large DNA sequences, especially in diagnosis.

\section{Conclusion}

In the present study, we show that the HRM approach allows for the screening of mutations across large DNA sequences. DNA samples that produce plots which are distinct from the wild-type, should be sequenced to confirm and identify the specific mutations, or SNPs. Finally, we demonstrate that the HRM approach, which is very sensitive, specific, cost-effective, and fast, can be used efficiently, especially in diagnosis.

\section{Competing interests}

The authors declare that they have no competing interests.

\section{Authors' contributions}

ME carried out the molecular genetic studies, took part in gathering the patients' recruitment and drafted the manuscript. BD participated in the analysis of the HRM curve. $\mathrm{KH}$ and $\mathrm{AB}$ revised the manuscript. MAS helped analyze the sequencing result. $A B$ assisted in the sequencing experiment. $\mathrm{HJ}$ and $A B$ coordinated the patient's recruitment and provided the clinical data. $A B$ supervised the sequencing experiment. SN conceived the study and participated in its design and coordination. All authors read and approved the final manuscript.

\section{Acknowledgements}

We gratefully acknowledge the members of LGMP and the Oncology department. We are also indebted to Amal TAZZITE for her help with the positive controls. This study was supported by Casablanca Hassan II University and Casablanca Medical and Pharmacy School.

\section{Author details}

${ }^{1}$ Genetics and Molecular Pathology Laboratory, Medical school of Casablanca, Casablanca, Morocco. ${ }^{2}$ Department of Oncology, Ibn Rochd University Hospital, Casablanca, Morocco. ${ }^{3}$ Laboratoire de Génétique Moléculaire Humaine, Département de la Recherche Scientifique, Institut Pasteur du Maroc, Casablanca, Morocco.

Received: 6 May 2014 Accepted: 23 January 2015

Published online: 25 February 2015

\section{References}

1. Hondow HL, Fox SB, Mitchell G, Scott RJ, Beshay V, Wong SQ, et al. A high-throughput protocol for mutation scanning of the BRCA1 and BRCA2 genes. BMC Cancer. 2011;11:265.

2. Takano EA, Mitchell G, Fox SB, Dobrovic A. Rapid detection of carriers with $B R C A 1$ and BRCA2 mutations using high resolution melting analysis. BMC Cancer. 2008;8:59.
3. Miki Y, Swensen J, Shattuck-Eidens D, Futreal PA, Harshman K, Tavtigian S, et al. A strong candidate for the breast and ovarian cancer susceptibility gene BRCA1. Science. 1994;266:66-71.

4. de Juan JI, Cardeñosa EE, Suela SP, González EB, Trejo DS, Lluch OF, et al. Advantage of high-resolution melting curve analysis over conformationsensitive gel electrophoresis for mutational screening of BRCA1 and BRCA2 genes. Clin Chim Acta. 2011;412:578-82.

5. Tazzite A, Jouhadi $H$, Nadifi S, Aretini P, Falaschi E, Collavoli A, et al. BRCA1 and BRCA2 germline mutations in Moroccan breast/ovarian cancer families: novel mutations and unclassified variants. Gynecol Oncol. 2012;125:687-92.

6. Tazzite A, Nadiffi S, Kottwitz D, El Amrani M, Jouhadi H, Benider A, et al. Specific BRCA1 gene variations amongst young Moroccan breast cancer patients. Genet Mol Res. 2014;13:791.

7. Ririe KM, Rasmussen RP, Wittwer $C T$. Product differentiation by analysis of DNA melting curves during the polymerase chain reaction. Anal Biochem. 1997;245:154-60.

8. De Leeneer K, Coene I, Poppe B, De Paepe A, Claes K. Rapid and sensitive detection of BRCA1/2 mutations in a diagnostic setting: comparison of two high-resolution melting platforms. Clin Chem. 2008;54:982-9.

9. Dufresne SD, Belloni DR, Wells WA, Tsongalis GJ. BRCA1 and BRCA2 mutation screening using SmartCycler II high-resolution melt curve analysis. Arch Pathol Lab Med. 2006:130:185-7.

10. Kroupis C, Christopoulos K, Devetzoglou M, Tsiagas I, Lianidou ES, Asymmetric real-time PCR detection of BRCA1 5382insC mutation by melting curve analysis in the LightCycler. Clin Chim Acta. 2008;390:141-4.

11. de Juan I, Esteban E, Palanca S, Barragán E, Bolufer P. High-resolution melting analysis for rapid screening of BRCA1 and BRCA2 Spanish mutations. Breast Cancer Res Treat. 2009;115:405-14.

12. Santos E, Paula J, Motta P, Heinemann M, Leite R, Haddad J, et al. Comparison of three methods of DNA extraction from peripheral blood mononuclear cells and lung fragments of equines. Genet Mol Res. 2009;9:1591-8.

13. Murphy PD. Method for determining the haplotype of a human BRCA1 gene. In: Book Method for determining the haplotype of a human BRCA1 gene, Google Patents. 2005.

14. Zhou L, Wang L, Palais R, Pryor R, Wittwer CT. High-resolution DNA melting analysis for simultaneous mutation scanning and genotyping in solution. Clin Chem. 2005;51:1770-7.

15. van der Stoep N, van Paridon CD, Janssens T, Krenkova P, Stambergova A, Macek $M$, et al. Diagnostic guidelines for high-resolution melting curve (HRM) analysis: An interlaboratory validation of BRCA1 mutation scanning using the 96-well LightScanner ${ }^{\mathrm{TM}}$. Hum Mutat. 2009;30:899-909.

16. De Leeneer K, Coene I, Poppe B, De Paepe A, Claes K. Genotyping of frequent BRCA1/2 SNPs with unlabeled probes: a supplement to HRMCA mutation scanning, allowing the strong reduction of sequencing burden. J Mol Diagn. 2009;11:415-9. 